\title{
Papers
}

\section{Random allocation or allocation at random? Patients' perspectives of participation in a randomised controlled trial}

Katie Featherstone, Jenny L Donovan

\begin{abstract}
Objectives To explore trial participants' understandings of randomisation.

Design In this exploratory study, which used qualitative research methods, in-depth, semistructured interviews were carried out with 20 participants from the CLasP randomised controlled trial. Interviews were recorded on audio tape and fully transcribed. Data were analysed by comparing transcripts and describing emergent themes, using a grounded theory approach.

Setting The CLasP study comprises three linked multicentre, pragmatic randomised controlled trials evaluating the effectiveness and cost effectiveness of laser therapy, standard surgery, and conservative management for men with lower urinary tract symptoms or urinary retention, or both, related to benign prostatic disease.

Subjects 20 participants in the CLasP study were interviewed. Sampling was purposeful: men were included from each of the treatment arms, the two major centres, and at different points in the trial. Interventions and outcome measures Interviews used a checklist of topics to encourage participants to describe their experiences. Narratives concerning randomisation were compared to identify common themes, retaining the context of the discussion to allow detailed interpretation.

Results Most participants recalled and described aspects of randomisation, such as the involvement of chance, comparison, and concealed allocation. Many found the concept of randomisation difficult, however, and developed alternative lay explanations to make sense of their experiences. Inaccurate patient information and lay interpretations of common trial terms caused confusion.

Conclusions The provision of clear and accurate patient information is important, but this alone will not ensure consistent interpretation of concepts such as randomisation. Patients may need to discuss the purposes of randomisation in order to understand them fully enough to give truly informed consent.
\end{abstract}

\section{Introduction}

The randomised controlled trial is the widely acknowledged design of choice for evaluating medical and surgical treatments. ${ }^{12}$ Though textbooks and reports of trials in journals focus on issues concerned with design, methods, and results, ${ }^{1-3}$ the patient's perspective is relatively neglected. Published research has mostly used questionnaires to examine attitudes towards participation in order to improve accrual. Satisfaction with trial participation is reported by $90-97 \%$ of patients. ${ }^{4-6}$ Those (75-93\% of respondents) who said they would participate in future trials cited altruism ${ }^{5-7}$ and personal benefit ${ }^{5689}$ as reasons. Difficulties with travelling and time taken were the only major criticisms. ${ }^{46}$ Studies of the public or outpatients indicate that $50-75 \%$ would probably participate, with $10-20 \%$ definitely refusing. ${ }^{810}{ }^{11-14}$ Interpretation of these studies is difficult because of their reliance on general issues or hypothetical trials, which do not have direct relevance to actual participation in real trials. Recent research has explored how patients' preferences might be incorporated within trials because of their potential influence on outcome. ${ }^{15-19}$

Two studies have used qualitative research methods to explore more detailed perceptions of methods and terms employed by trials. Roberson et al found that although respondents were familiar with the term "experimental study," two thirds had not heard the term "clinical trial." ${ }^{20}$ Snowdon et al, using in-depth interviews with parents of critically ill babies, found that the nature of the trial was often poorly understood and that there were particular problems with the concept of random allocation, and considerable confusion and anger relating to parents' desire for the most suitable treatment for their child. ${ }^{21}$

The existing research record has tended to focus on hypothetical questions, often in trials of rare conditions, or in Snowdon et al's case, parents of critically ill babies. ${ }^{21}$ The study reported here uses qualitative research methods to elicit the perspectives of "ordinary" middle aged and elderly men who require elective treatment for a common condition and who have themselves agreed to participate in a pragmatic randomised controlled trial. This paper focuses on the ways in which they make sense of the concept that lies at the heart of the randomised controlled trial: random allocation.

\section{Patients and methods}

The study involved patients eligible for the CLasP study. This comprises three linked pragmatic randomised controlled trials to evaluate the effectiveness

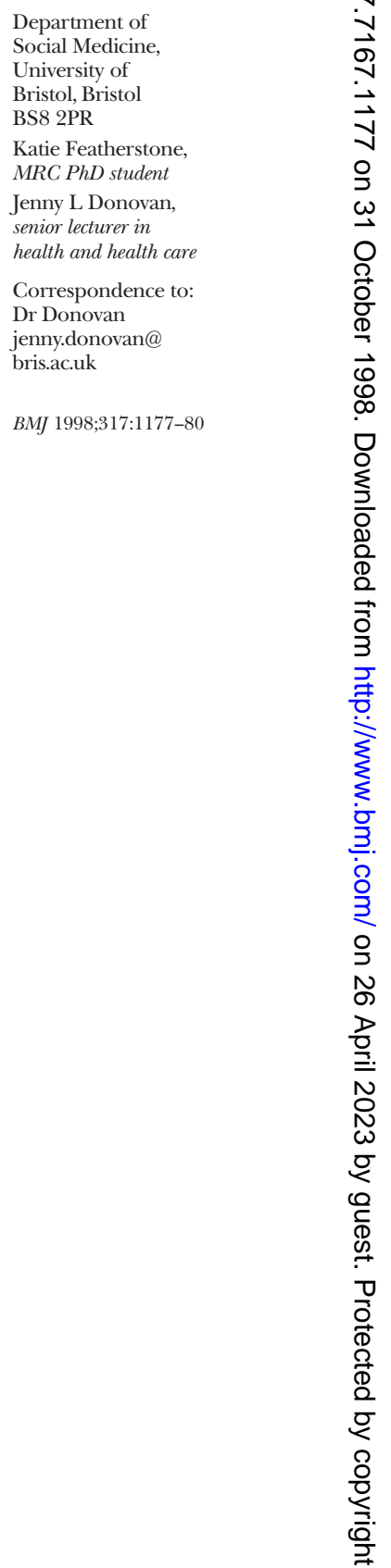


of a new technology (laser therapy) compared with standard surgery (transurethral resection of the prostate-TURP) for men with acute or chronic urinary retention; and laser, surgery, and conservative management (monitoring without active intervention) for men with lower urinary tract symptoms related to benign prostatic disease. The aims of this substudy, to explore the perspectives of patients who agreed or refused to participate in CLasP, meant that qualitative research methods were most appropriate. ${ }^{22}$

Sampling in qualitative research uses nonprobability methods, including "purposeful" sampling, in which individuals with particular characteristics are deliberately and systematically selected to explore emerging analytical themes. In this study, 20 participants were interviewed; they came from each of the major clinical centres (11 from A, nine from B), different treatment arms (five conservative management, eight laser therapy, seven TURP), and at different time points (seven within 3 months and five within 5 months of randomisation, and eight after receiving treatment). Men who chose not to participate were also interviewed (these data will be reported elsewhere).

Data were collected by in-depth interviews carried out by $\mathrm{KF}$ using a semistructured checklist of topics, ${ }^{23-25}$ covering the same basic issues, including initial symptoms; recall, understanding, and experience of recruitment; feelings about participation; experiences of treatment; and outcome. The aim was to encourage the men to relate stories about their experiences and to explore their understandings of what had happened. Interviews were conducted in the men's homes and recorded on audio tape; they lasted from half an hour to one and a half hours. Each interview was transcribed by $\mathrm{KF}$ verbatim, including descriptions of non-verbal factors where appropriate. Analysis of the data proceeded by detailed scrutiny of the transcripts to identify common themes, which were coded; these coded segments of text were included in separate word processing files. ${ }^{26}$ These files were expanded with new transcripts and refined, focused, or altered as new themes emerged. Each individual's narrative was examined independently to assess the coherence of each account. Data collection and analysis continued concurrently, according to constant comparison methods of grounded theory, in which data are examined for similarities and differences within themes, retaining the context of the discussion and characteristics of the individuals to aid understanding and allow interpretation and the development of explanations of findings. ${ }^{27}$

Treatment in the CLasP study was allocated to each patient after he had given written informed consent and completed questionnaires and clinical tests, and was done by clinical researchers opening consecutive opaque envelopes. Patients were given an information sheet that described the study as a randomised controlled trial and said that it involved comparing treatments, that one treatment was new (laser therapy), that there was uncertainty about which treatment was best, and that allocation would be by chance and by a clinician opening a sealed envelope.

The results relating to the experience and understanding of randomisation are presented below according to the themes which emerged from the interview data, although space does not permit detailed descriptions of the context surrounding these data. Illustrative quotations are provided, selected for their relevance to the themes and so that the reader can judge the interpretations of the researchers. Names have been changed to protect confidentiality.

\section{Results}

\section{Understanding randomisation}

Almost all the participants were aware of some aspects of randomisation, and most (14/20) acknowledged the involvement of chance in the allocation of their treatment. Often this was transformed into a description of other (lay) examples of chance, such as a lottery or lucky dip:

Mr Cooper: But anyway I agreed to have a go at it, a bit of a lucky dip. She has them in envelopes, which operation you are going to get, or which method of treatment you are going to get.

Mr Symonds: He said, oh yes you've got a swollen prostate, you'll probably have to have an operation but it's a chance you might take, which one of them you take, it comes out the hat, sort of thing you know. It's out of the hat, you cannot pick.

Around half of the men (11) talked about the study in terms of it being a comparison between treatments or an experiment, with the treatment allocation being unknown until the contents of an envelope were revealed:

Mr Taylor: She told me that I would either have the laser treatment or the operation .... and at the same time explained that neither she nor the consultant himself knew which I would get until they chose this famous envelope.

A smaller number (four) were also more explicit about clinical equipoise - that the doctor did not know what treatment was best:

Mr Murray: They were unbiased, didn't give you any impression that one was better than the other. But the scheme itself was-I think they wanted to compare, they wanted to do all three and then make a comparison of what the end results were.

\section{Explaining treatment allocation}

The majority of men developed detailed narratives to describe and explain their understanding of the method of treatment allocation. While most were able to describe aspects of randomisation, such as the involvement of chance, need for comparison, and concealed allocation, often their narratives contained other lay explanations of what they thought had happened or should have happened. Sometimes this was caused by a clash between experience and expectation-for example, where they had not seen the clinician open the envelope as expected:

Mr Mills: When she first explained it, she said you'll be given an envelope and you take your pick, apparently, and that never happened ... . I never got offered any envelope. I was just ... that was the treatment they more or less picked out for me.

Perhaps the most difficult concept for patients to comprehend was clinical equipoise. Lay beliefs and previous experience meant that the men expected clinicians to assign them to treatment based on their specific symptoms, clinical findings, and age:

Mr Symonds: They still let you do the three card trick and they just carry it on because from the very first start it is 
written in the pamphlets they give you .... You've got your three choices, your TURPs, your-what do you call it [laser therapy], this one where you're under management, but I think it would be even better if they were to tell you that they prefer, what you're going to get .... I think that would be better than they let you take your pick when I think, along the lines, that you know you're being conned.

Mr Webster: Well [randomisation] was a bit confusing. It was. They know what's wrong with us. I thought it would just be one operation and that was it. If it was an operation, or if they could have cured it by medication, they would have decided there and then. The other consultant would have decided-you know, this lad need medication, or, yes, this lad needs the operation. KF: Did that surprise you? Mr Webster: Yes it did actually, it did. I could understand it, but I couldn't realise, cope with the idea that whatever the symptoms were, that was the envelope we were going to get .... I just thought that ... if it wasn't too bad, I would get the medication ... but it just seems that they're tossing a coin in the air.

Other common lay views revolved around the influence of fate, luck, and trust:

Mr Grange: I must say that I was fairly convinced that I was going to get a laser operation. I don't feel at all that those envelopes had anything to do with it.

Mr Cooper: I preferred the one that I got, so I must have been lucky.

Although the majority of men were able to discuss randomisation, two patients, both from the same centre and randomised to laser therapy, did not believe that their allocation was different from normal clinical practice. Apart from these two, levels of knowledge about randomisation and development of alternative accounts were similar between centres and across treatment arms.

\section{Meanings of trial terms}

Another complicating issue was the lay understanding of common terms often used by trialists with specific meanings but which have other meanings outside the confines of randomised controlled trials, such as "trial" and "random." In lay language, the word trial means something that is tried out, while "at random" relates to things being done without purpose:

Mr Bowler: She said there was three options which I had already read about. One was tablets, one was the ordinary operation, and one was laser. I didn't really realise that it was this scheme whereby they were, a trial, you know. Because I didn't think the other one is a trial-TURP. It's longstanding, isn't it?

Mr Flint: Well, I suppose there's a random system. There isn't a better way really. I mean, if it was just done randomly like that without anybody looking to see how certain results had gone and say "oh well, we'll take that one for there, we'll do this one there." If it was done randomly like that, then I suppose it's as good as any.

\section{Discussion}

\section{Randomisation and treatment allocation}

Most patients were able to describe some aspects of the concept of randomisation, particularly in terms of the involvement of chance, with some having a more detailed understanding of treatment comparison, concealed allocation, and experimental design. In response to a structured questionnaire about randomisation, most would probably have been shown to understand the concept in these basic terms. Qualitative research has shown that individuals routinely attempt to make sense of events by interpreting them in the context of their existing beliefs. ${ }^{28}{ }^{29} \mathrm{In}$ attempting to make sense of their participation in this trial, these men produced narratives which on the one hand described their understanding of elements of randomisation, but on the other hand challenged these understandings with, for example, accounts about trusting clinicians to make treatment allocations on the basis of individual clinical characteristics.

The existence of different accounts about treatment allocation could indicate confusion or distortion, as has been suggested elsewhere. ${ }^{21}$ The men in this trial acknowledged that randomisation was confusing (see Mr Webster above). Closer examination, however, shows that these apparently contradictory accounts are consistent in their own terms. The men's view that treatment should be determined by clinical and personal characteristics (symptoms or age) is reinforced by the number and complexity of tests and questionnaires they complete during the trial. Any confusion that arises comes from their attempts to make sense of their experience by trying to piece together apparently contradictory accounts-not from a lack of understanding of randomisation.

\section{Information and consent}

The terminology used in trials can have different meanings to participants and trialists. The lay definition of "random" (see Mr Flint), implies that treatments are allocated without purpose or control. Similarly, "trial" means that something is being "tried and tested" (see Mr Bowler). Mr Bowler is able to believe that laser therapy is "on trial" but has difficulty with the idea that the standard operation, TURP, is still "on trial." Similar lay definitions have been found elsewhere..$^{20}$

Also of importance is consistency between information given to participants and actual practice. In the CLasP study, information given to patients indicated that clinicians would open treatment allocation envelopes in front of patients. In practice, this was not possible. For some, not seeing the envelopes suggested that treatment could have been determined by clinicians. For Mr Symonds, it was the source of distrust about the study. Patient information needs to be clear about procedures to avoid such misinterpretation.

Perhaps more important are the implications for informed consent. Many of these men were struggling to come to terms with different (sometimes competing) views about randomisation. Although all had given written informed consent, it is evident that the majority did not hold a consistent explanation of the scientific method underlying the research. Further research is required to investigate whether these views are found more widely. It is also not clear what impact such beliefs may have on outcome, although some patients were upset by the difficulty of reconciling their views. Some patients doubted the veracity of the trial.

\section{Conclusion}

Although this study confirms the importance of providing clear and accurate patient information, it also shows that this in itself is unlikely to ensure consistent interpretation of concepts such as randomisation by participants. The patient information in this study was well received and largely accurately recalled, 
Key messages

- Most trial participants were able to recall and describe various aspects of randomisation, including the involvement of chance, comparison, and concealed allocation

- The majority found the concept of randomisation difficult to accept and developed other accounts to make sense of their experiences

- The use of terms which have different meanings to lay and professional audiences (such as trial and random) can cause confusion among participants

- Providing clear and accurate patient information is crucial, but to give truly informed consent patients may also need time to discuss the purposes of clinical trials and concepts such as randomisation

but patients still struggled with the concepts underlying the design and sometimes developed coexisting contradictory accounts. It may be that participants need to discuss the reasons for particular methods of trial design (such as randomisation) with researchers and reflect on these in order to understand them fully enough to give true informed consent. It is not clear, however, whether this greater understanding would lead to higher or lower levels of accrual to trials, but such an investigation could be linked with research attempting to incorporate patient preferences into randomised controlled trials. ${ }^{15} 16$

We acknowledge the support of the clinicians involved in the CLasP trial and thank the participants for agreeing to be interviewed for this study.

JD initiated the study. KF carried out the interviews and data analysis. JD confirmed the accuracy of the data analysis. JD and $\mathrm{KF}$ wrote and are guarantors for the paper.

Funding: This study was funded by the Medical Research Council as a PhD studentship. The CLasP study was funded by the South and West and Northern Regional Research and Development Directorates.

Competing interests: None declared.

1 Altman DG. Better reporting of randomised controlled trials: the CONSORT statement. BMJ 1996;313:570-1.

2 Pocock SJ. Clinical trials: a practical approach. Chichester: Wiley, 1983.

3 Senn S. Statistical issues in drug development. Chichester: Wiley, 1997.

4 Henzlova MJ, Blackburn GH, Bradley EJ, Rogers WJ. Patient perception of a long-term clinical trial: Experience using a close-out questionnaire in the studies of left-ventricular dysfunction (SOLVD) trial. Control Clin Trials 1994;15:284-93.
5 Suchanek Hudmon K, Stoltzfus C, Chamberlain RM, Lorimor RJ, Steinbach G, Winn RJ. Participants' perceptions of a phase I colon cancer chemoprevention trial. Control Clin Trials 1996;17:494-508.

6 Schron EB, Wassertheil-Smoller S, Pressel S. Clinical trial participant satisfaction: survey of SHEP enrollees. J Am Geriatr Soc 1997;45:934- 38.

7 Bevan EG, Chee LC, McGhee SM, McInnes GT. Patients' attitudes to participation in clinical trials. Br J Clin Pharmacol 1993;35:204- 7.

8 Mattson ME, Curb JD, McArdle R, and the AMIS and BHAT Research Groups. Participation in a clinical trial: the patients' point of view. Control Clin Trials 1985;6:156- 67.

9 Daugherty C, Ratain MJ, Grochowski E, Stocking C, Kodish E, Mick R, et al. Perceptions of cancer patients and their physicians involved in phase I trials. J Clin Oncol 1995;1:1062-72.

10 Cassileth BR, Lusk EJ, Miller DS, Hurwitz S. Attitudes toward clinical trials among patients and the public. JAMA 1982;248:968-70.

11 Slevin M, Mossman J, Bowling A, Leonard R, Steward W, Harper P, et al. Volunteers or victims: patients' views of randomised cancer clinical trials. Br J Cancer 1995;71:1270-4.

12 Rimer BK, Schildkraut JM, Lerman C, Lin TH, Audrain J. Participation in a women's breast cancer risk counselling trial. Who participates? Who declines? High Risk Breast Cancer Consortium. Cancer 1996;77(suppl): 2348-55.

13 Llewellyn-Thomas HA, McGreal MJ, Thiel EC, Fine S, Erlichman C. Patients' willingness to enter clinical trials: measuring the association with perceived benefit and preference for decision participation. Soc Sci Med 1991;32:35-41.

14 Bartholow BN, Macqueen KM, Douglas JM Jr, Buchbinder S, McKirnan $\mathrm{D}$, Judson FN. Assessment of the changing willingness to participate in phase III HIV vaccine trials among men who have sex with men. J AIDs Hum Retrovirol 1997;16:108-15.

15 Kassirer JP. Incorporating patients' preferences in medical decisions [editorial]. N Engl J Med 1994;330:1895-6.

16 Silverman WA. Patients' preferences and randomised trials. Lancet 1996;347:1714.

17 Brewin CR, Bradley C. Patient preferences and randomised clinical trials. BMJ 1989;299:313-5.

18 McPherson K. The best and the enemy of the good: randomised controlled trials, uncertainty, and assessing the role of patient choice in medical decision making. J Epidemiol Community Health 1994;48:6-15.

19 Sutherland HJ, Llewellyn-Thomas HA, Lockwood GA, Tritchler DL, Til JE. Cancer patients' desire for participation in treatment. J R Soc Med 1989;82:260-3.

20 Roberson NL. Clinical trial participation. Viewpoints from racial/ethnic groups. Cancer 1994;74(suppl):2687-91.

21 Snowdon C, Garcia J, Elbourne D. Making sense of randomization: responses of parents of critically ill babies to random allocation of treatment in a clinical trial. Soc Sci Med 1997;45:1337-55.

22 Pope C, Mays N. Reaching the parts other methods cannot reach: an introduction to qualitative methods in health and health services research. BMJ 1995;311:42-5.

23 Burgess RG. The unstructured interview as a conversation. In: Burgess RG, eds. Field research: a source book and field manual. London: Routledge, 1982:107-10.

24 Hammersley M, Atkinson P. Ethnography: principles in practice. London: Tavistock, 1983.

25 Mays N, Pope C, eds. Qualitative research in health care. London: BMJ Publishing Group, 1996.

26 Miles MB, Huberman EM. Qualitative data analysis. 2nd ed. London: Sage, 1994.

27 Glaser BG, Strauss AL. The discovery of grounded theory. Chicago: Aldine, 1967.

28 Schutz, A. The phenomenology of the social world. London: Heinemann Educational, 1972

29 Williams G. The genesis of chronic illness: narrative reconstruction. Sociol Health Illness 1984;6:175-200.

(Accepted 1 October 1998)

\section{Fifty years ago}

\section{The new NHS: The BMA under fire}

To defend the BMA by saying (Aug 21, p 392) that no organization is perfect but, so long as it acts in good faith and with courage, it can withstand criticism recalls Mr. Churchill's remark about our pre-war Government - that it is a fine thing for a Prime Minister to be honest but an important thing for a Prime Minister to be right. Was the BMA right in refusing to allow any discussion of terms of service during the past six years? It has been obvious for all of that time that sooner or later the BMA would offer the services of the profession to the country. When any of us is going to sell something important his first step is to get an opinion of what it is worth: satisfactory negotiation is impossible otherwise. The BMA had a real duty to find out what value the profession put on its services. The evidence given to the Spens Committee would pretty certainly have been affected by such information. It is a doubtful argument to say that a majority of practitioners have approved the Spens Report. A majority of practitioners opposed the health service in the second plebiscite, but the minority view was adopted then. Anyhow, if the BMA had put discussion of terms on divisional agendas years ago it would have been in a far better position to appreciate the difficulties of what it regards as a minority now, instead of spending six years on principles, of which it evolved seven, or slightly more than one principle per annum. I challenge any reader to write down at once those principles (if he remembers them), to reflect on how many have proved essential, and to say that they justify six years of planning committees and executive, divisional, representative, and council meetings. So far as the health service goes no other result emerged. W A Bourne, Sussex.

(Letter, 4 September 1948, p 499. See also editorial by Gordon Macpherson, 3 January 1998, p 6.) 